\title{
Thermochemical Reduction of Carbon Dioxide with Alkali Metal Hydrides, Producing Methane and Hydrogen Fuels at Moderate Temperature
}

\author{
Bao-Xia Dong*, Long-Zheng Wang, Liang Song, Juan Zhao, Yun-Lei Teng*
}

College of Chemistry and Chemical Engineering, Yangzhou University, Yangzhou, 225002, P. R. China
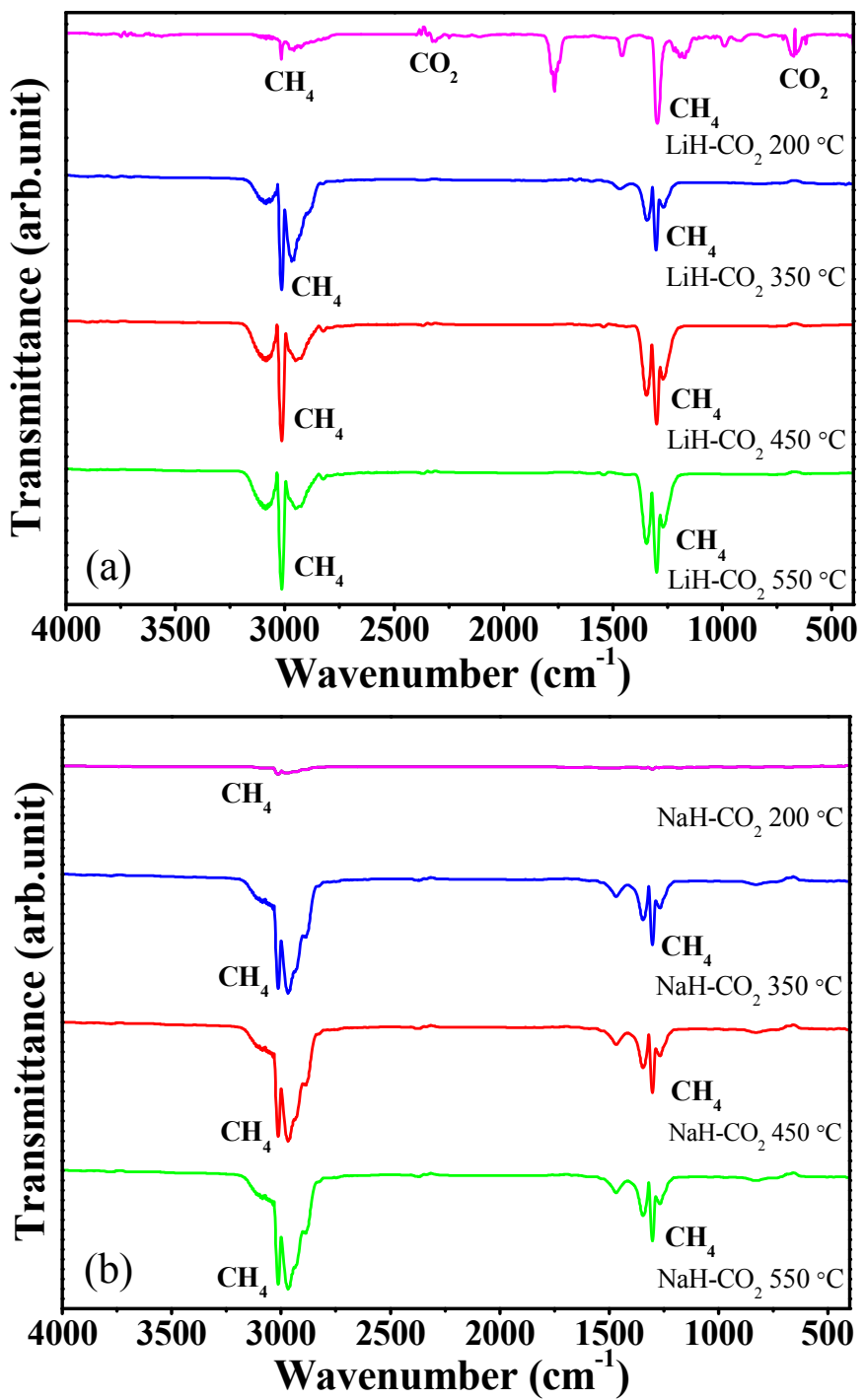

Figure. S1 FTIR spectra of the gas products for the reactions of the ball-milled MH $(\mathrm{M}=\mathrm{Li}$ or $\mathrm{Na})$ with $\mathrm{CO}_{2}\left(0.25 \mathrm{MPa}, \mathrm{MH} / \mathrm{CO}_{2}=4 \mathrm{~mol} / \mathrm{mol}\right)$ at 200,350 and $550{ }^{\circ} \mathrm{C}$ for $48 \mathrm{~h}$. 

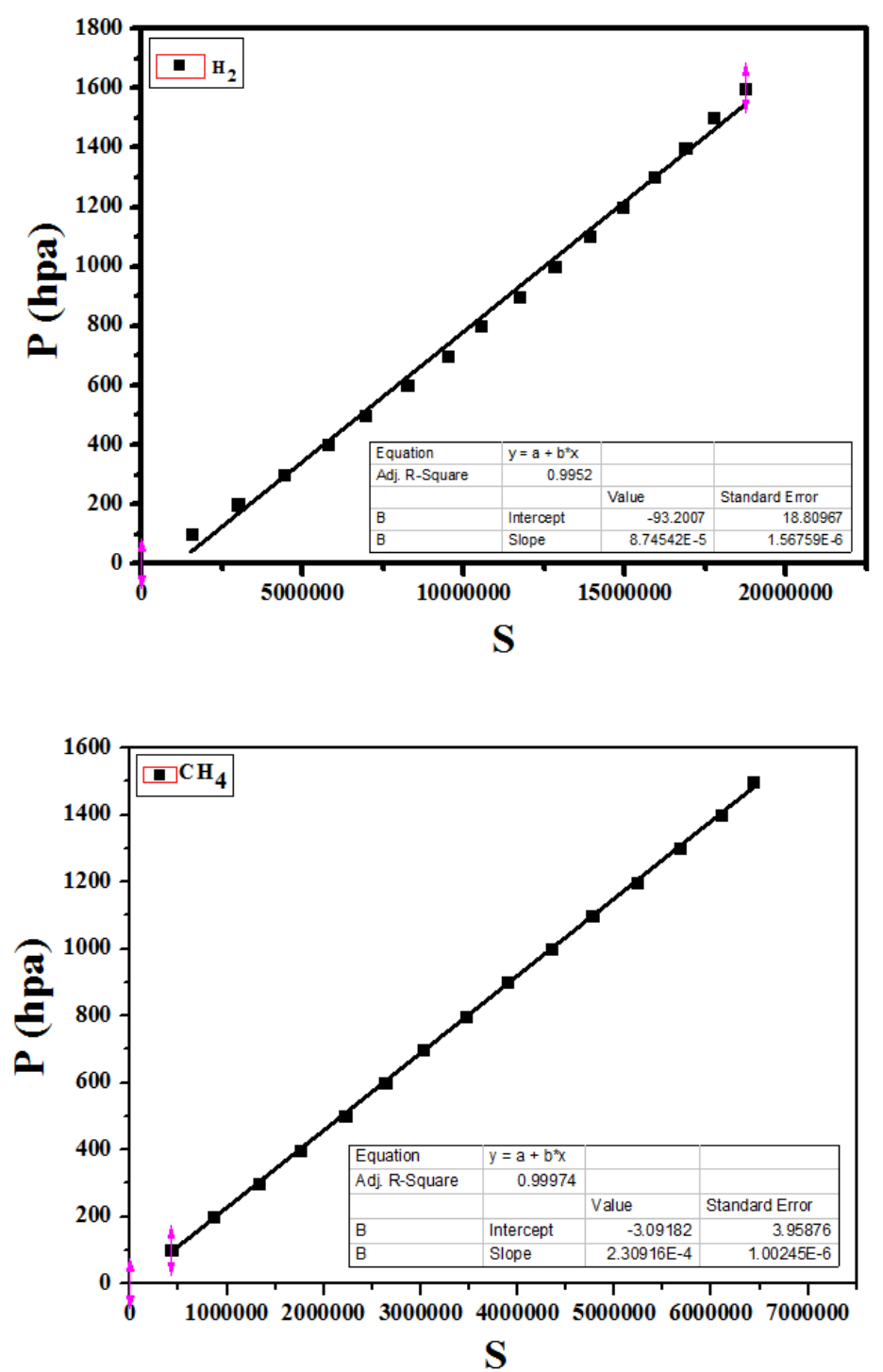

Figure S2 Standard curves for pure hydrogen and pure methane established on $5 \AA$ molecular sieve for GC analysis. 


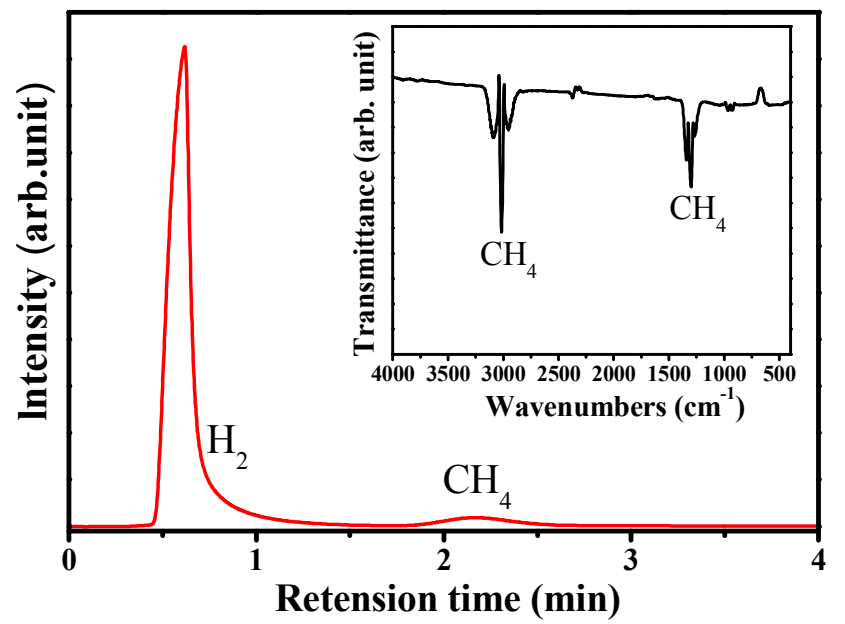

Figure. S3 GC profiles and FTIR spectra of the gas products for reactions of the ball-milled active carbon with $\mathrm{H}_{2}$ at $450{ }^{\circ} \mathrm{C}$ for $48 \mathrm{~h}$. 